\title{
Haemonchus contortus Infection and Associated Pathological Changes in a Goat (Capra hircus)
}

\author{
Shailesh Kumar Patel ${ }^{1}$, Jigyasa Rana ${ }^{2 *}$, Poornima Gumasta ${ }^{1}$, Dhananjay Kumar Jolhe ${ }^{1}$ \\ Pankaj Kumar Patel ${ }^{3}$ and Anish Kumar Sonwani ${ }^{1}$ \\ ${ }^{1}$ Department of Veterinary Pathology, College of Veterinary Science \& A.H., CGKV, Anjora, \\ Durg-491001 Chhattisgarh, India \\ ${ }^{2}$ Department of Veterinary Anatomy and Histology, Nagpur Veterinary College, MAFSU, \\ Nagpur-440006 Maharashtra, India \\ ${ }^{3}$ Division of Medicine, ICAR-Indian Veterinary Research Institute, Izatnagar-243122, India \\ *Corresponding author
}

\section{A B S T R A C T}

\section{Ke y w o r ds \\ Goat, Haemonchus contortus, \\ Abomasum, Faecal examination, \\ McMaster technique}

Article Info

Accepted:

18 February 2019

Available Online:

10 March 2019
An adult female goat was presented for the post-mortem examination to the Department of Veterinary Pathology, College of Veterinary Science \& A.H., Anjora, Durg, Chhattisgarh. The animal had emaciated body, pale mucous membranes with the history of anorexia and loss of body weight. Upon necropsy, the internal organs were found extremely pale, which was suggestive of anaemia. Liver of the animal was hemorrhagic and enlarged. Abomasum of the animal was found filled with the blood-sucking parasites Haemonchus contortus spp. and severe abomasitis was observed. Fecal sample collected for microscopic examination revealed 1150 egg per gram indicating severe parasitic infestation.

\section{Introduction}

The alimentary canal of vertebrate represents one of the most favorable habitats for numerous helminths that cause structural and functional changes in the digestive tract (Berrilli et al., 2012). Pathological effects due to parasitic infection are varied and more pronounced in sheep and goat compared to those seen in other species of livestock (Iqbal et al., 1993). Haemonchus contortus is an important blood-sucking parasite of sheep and causes an insidious drain on production (Hussain et al., 1967). Although the parasite is prevalent wherever sheep and goats are raised, but it exerts the greatest economic losses in temperate and tropical regions (Blood, 1979). Haemonchus contortus is a blood-sucking parasite generally found in the abomasum of the sheep and goat causes 
significant loss of blood. Each worm sucks around $0.05 \mathrm{ml}$ blood per day resulting production loss, severe anaemia and even death of the animal (Urquhart et al., 1987).

In the present study severe parasitic infection of Haemonchus contortus in a goat has been reported.

\section{Materials and Methods}

A female goat of three years of age was presented for the post-mortem examination to the Department of Veterinary Pathology, College of Veterinary Science \& A.H., Anjora, Durg Chhattisgarh. The detailed necropsy examination was carried out and all the gross pathological changes were recorded carefully. Faecal sample collected from the abomasum and different parts of the intestine during necropsy examination subjected to the qualitative and quantitative examination.

A qualitative examination of faecal Sample has been performed by saturated salt solution, knowing the fact that parasitic ova, being lighter, float on the top of fluid and thus can be concentrated for examination. Briefly, $1 \mathrm{~g}$ faecal sample was taken, mixed with few milliliters of distilled water and filtered through a fine sieve. The filtrate was centrifuged and the supernatant was discarded. The sediment was mixed with 4-5 $\mathrm{ml}$ of saturated salt solution. The material was transferred into a tube and filled up to the top with a saturated salt solution. A clean glass coverslip was placed on the mouth of the tube and left for 30 minutes. Finally, the coverslip is removed and examined under a microscope for the presence of eggs (Chauhan and Chandra, 2007).

The quantitative examination was performed by the McMaster technique. In this method, 2 $\mathrm{g}$ of faecal sample was collected in a beaker and $28 \mathrm{ml}$ of distilled water was added followed by proper mixing. $1 \mathrm{ml}$ of an above mixture (faecal suspension) was mixed with $1 \mathrm{ml}$ of saturated sugar solution. A drop of the solution was placed into McMaster slide to cover the counting chamber and was left for a few minutes. The eggs were counted using a microscope. To calculate eggs per gram of faeces, total count (Chamber $1+$ Chamber 2) was multiplied with 50 (Lyndal-Murphy, 1985).

\section{Results and Discussion}

The clinical history taken from the farm manager revealed that the housed animals were dull, anorectic, pale and reducing weight constantly. External body condition of the animal was rough and emaciated along with pale conjunctiva (Fig. 1A). Post mortem examination showed extreme pale viscera indicating severe anaemia (Fig. 1B). Serous exudates were found in the abdominal cavity.

Lungs of the animal were found pneumonic and liver was slightly enlarged and hemorrhagic. Abomasum of the goat was found filled with the adult Haemonchus spp. most of the parasites were found attached with the mucous membrane and some were mixed with the ingesta. Pathological lesions like the change in colour from pale to pink, excess secretion of mucous and development of oedematous folds have been observed in the abomasum (Fig. 1C). Haemonchus contortus parasite was identified by observing bursa of male (Fig. 2B) and vulvar flap of female (Fig. 2C).

Fecal sample subjected to qualitative examination revealed abundant eggs of Hemonchus spp. (Fig. 2A). Quantitative examination of the faecal sample revealed 1150 EPG (egg per gram) showing the severe category of parasitic infection indicating the requirement of treatment of the surviving goats (Machen et al., 1998). 
Fig.1 A: Showing pale conjunctiva of dead goat; B: Showing extremely pale viscera of the goat; $\mathrm{C}$ : Showing congested mucous membrane of abomasum along with oedema
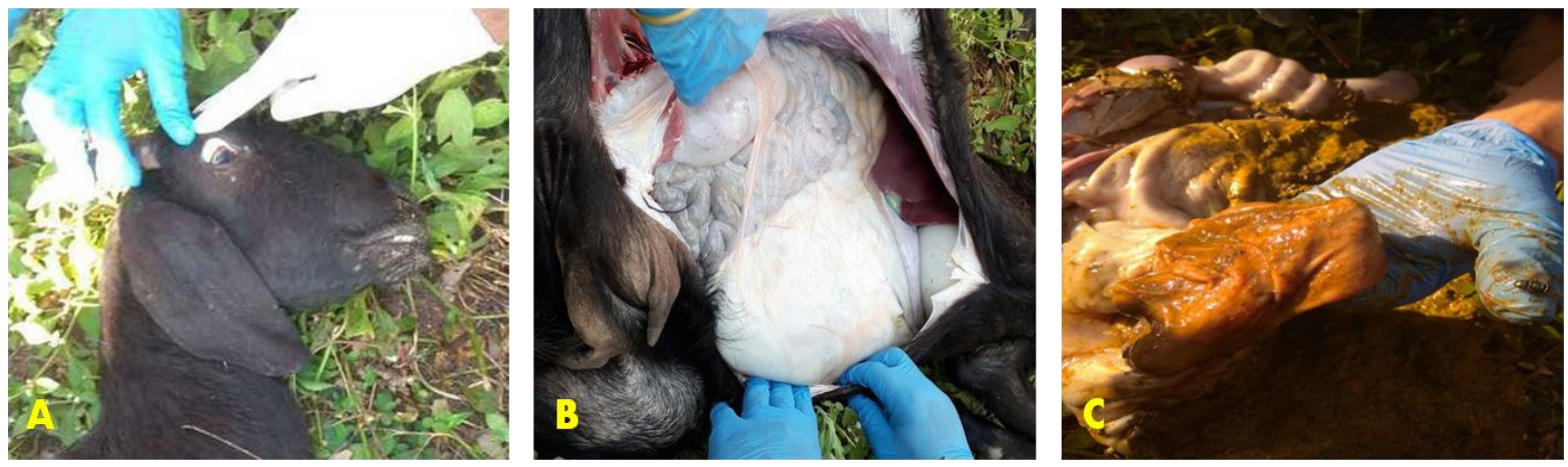

Fig.2 A: Eggs of Haemonchus spp. parasite (x400); B: Showing bursa of the male parasite (x400); C: Showing vulvar flap of the female parasite (x100)

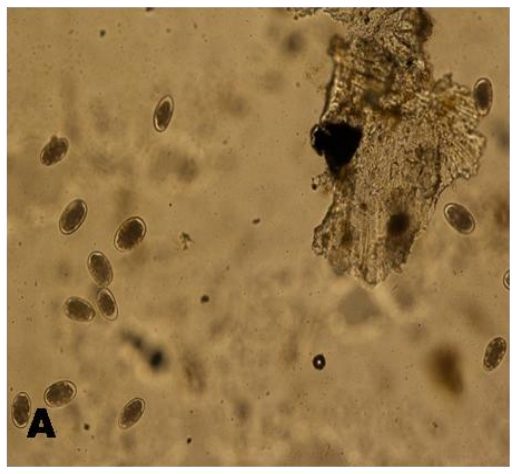

Our results corroborated with many researchers. Dutta et al., (2017) reported highly anaemic carcass with pale to papery white visible mucous membranes. In most cases, the carcasses were emaciated and abomasal contents were mixed with blood and a large number of adult Haemonchus contortus parasites. Oedematous folds, petechial haemorrhage and nodule formation in the infected abomasum may be due to the piercing activity of the worm (Tehrani, 2012). Rinaldi et al., (2011) suggested that over secretion of mucous in the parasitized abomasum may be due to host reaction against parasite for their defense, as it has been reported that mucous layer acts as a physical barrier for microorganisms, parasites and their toxins. Faecal eggs of Haemonchus contortus was also identified by Dutta et al., (2017) in his study which was similar to our case.

In conclusion, the present case indicated that animal was suffering from severe parasitic infection leading to anaemia and immunosuppression resulting in the death of the animal. This also provided an idea of heavy worm infestation of that particular farm requires antihelminthic drug treatment as soon as possible.

\section{References}

Bailly, V., Zhang, Z., and Meier, W. 2002. Shedding of kidney injury molecule-1, a putative adhesion protein involved in 
renal regeneration. Journal of Biological Chemistry. 277: 3973939748.

Berrilli, F., Di Cave, D., Cavallero, S. and D'Amelio, S. 2012. Interactions between parasites and microbial communities in the human gut. Frontiers in Cellular and Infection Microbiology.2: 141.

Blood, D. C., Henderson, J. A., and Radostits, A. M. 1979. Veterinary Medicine. 5th Ed., Bailliere Tindall, London, UK.

Chauhan, R.S. and Chandra, D. 2007. Veterinary Laboratory Diagnosis. $2^{\text {nd }}$ Ed., International Book Distributing Co. Lukhnow.

Dutta, B., Konch, P., Rahman, T., Upadhyaya, T. N., Pathak, D. C., Phangchoo, C. V., and Begum, S. A. 2017. Occurrence and pathology of Haemonchus contortus infection in Goats. Journal of Entomology and Zoology Studies. 5(3): 1284-1287.

Hussain, M. Z., and Akram M. 1967. Hostparasite relationship Studies on the productivity of sheep as affected by haemonchosis. Pakistan Journal of Medical sciences.5: 247-251.

Iqbal, Z., Akhtar, M., Khan, M. N. and Riaz, M. 1993. Prevalence and economic significance of Haemonchosis in sheep and goats slaughtered at Faisalabad abattoir. Journal of Agricultural Science. 30: 51-53.
Lyndal-Murphy. 1985. The modified McMaster method. In Anthelmintic Resistance in Sheep. Queensland, Australia: Animal Research Institute, Queensland Department of Primary Industries 8.

Machen, R., Craddock, F., Craig, T., and Fuchs, T. 1998. A Haemonchus contortus Management Plan for Sheep and Goats in Texas. Pamphlet L-5095. College Station, T.X.: AgriLife Communications, Texas A\&M System.

Rinaldi, M., Dreesen, L., Hoorens, P. R., Li, R. W., Claerebout, E., Goddeeris, B., Vercruysse, J., Broek, W. V. D., and Geldhof, P. 2011. Infection with the gastrointestinal nematode Ostertagia ostertagi in cattle affects mucus biosynthesis in the abomasum. Veterinary Research.42: 61.

Tehrani, A., Javanbakht, J., Jani, M., Sasani, F., Solati, A., Rajabian, M., Khadivar, F., Akbari, H., and Mohammadian, M. 2012. Histopathological Study of Haemonchus contortus in Herrik Sheep Abomasum. Journal of Bacteriology and Parasitology. 3 (5): 144.

Urquhart, G. M., Armour, J., Duncan, J. L., Dunn, D. M., and Jennings, F. W. 1987. Veterinary parasitology. English Language Book Society, England.

\section{How to cite this article:}

Shailesh Kumar Patel, Jigyasa Rana, Poornima Gumasta, Dhananjay Kumar Jolhe Pankaj Kumar Patel and Anish Kumar Sonwani. 2019. Haemonchus contortus Infection and Associated Pathological Changes in a Goat (Capra hircus). Int.J.Curr.Microbiol.App.Sci. 8(03): 2111-2114. doi: https://doi.org/10.20546/ijcmas.2019.803.252 